\title{
Study on the Green Construction Supervision Based on Evolutionary Game Theory
}

\author{
Zhongfu Qin ${ }^{1, a}$, Wei Wei ${ }^{1, b^{*}}$ and Min Qin ${ }^{1, c}$ \\ ${ }^{1}$ A523, An-zhong Building, 866 Yuhangtang Road, Hangzhou, China

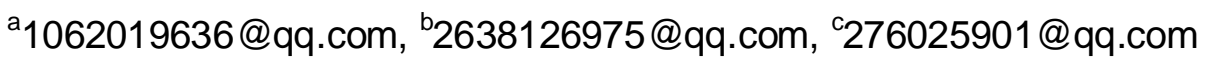

*The corresponding author

Keywords: Green construction; Evolutionary game; System stability; Regulatory strategy

\begin{abstract}
Under the green construction policy, this paper analyzes the game relationship between construction enterprise and supervision department, and sets up a green construction supervision evolutionary game model based on the replicated dynamic equation. By means of Jacobin matrix and other nonlinear system analysis methods, the stability of the equilibrium point of the game system is studied, and the factors that affect the level of green construction are analyzed. The result shows that there is no stable equilibrium in the static game system. After the supervision department takes the dynamic penalty strategy, the game system has an evolutionary stable equilibrium point. Improving the punishment and reward of the regulatory authorities or reducing regulatory costs, can effectively improve the level of green construction.
\end{abstract}

\section{Introduction}

With the increasingly prominent problems of resources and environment, green construction has been paid more and more attention by the society. As the spokesman of the public, how to set up scientific and reasonable supervision strategy and promote the development of green construction is a topic worthy of study and discussion.

Many scholars have studied the promotion and motivation of green construction: Huang Yuqi outlined the green construction policy system in Beijing and Shanghai for nearly 10 years [1]. Based on cost-benefit perspective, $\mathrm{Xu}$ Lei put forward the countermeasures and suggestions to speed up the green construction from two aspects of the micro economic benefits of enterprises and the government's macro intervention [2]. Xiao Xuwen believes that should accelerate the construction of green construction standards and regulations system, which strongly promote the implementation of green construction [3]. Wang Xu using ANP method established influencing factors model of green construction application in construction enterprises, and concluded that the construction enterprises and the government departments will have the game in the process of implementing green construction [4]. Lin Yu identified 27 driving factors of green construction of construction enterprises from 4 aspects of government, society, market and enterprise itself, and put forward the countermeasures and suggestions for the construction enterprises in different stages[5]. The present research is more inclined to the qualitative analysis; there are few quantitative researches on the interaction mechanism between the two key parts of the green construction, the construction enterprise and the government supervision department.

The evolutionary game was formally proposed by Maynard Smith and Price (1973) in the study of biological conflict [6], it has been widely used in the fields of economics and sociology subsequently. Different from the traditional game theory under the completely rational person hypothesis, the evolutionary game model is constructed based on the choice of people and the mutation behavior under the premise of bounded rationality [7]. Evolutionary game provides an effective mathematical tool for describing the game of many players, it has been used to analyze complex issues such as industrial policy, innovation management, and environmental governance [8-10], and however, there is no literature on the green construction supervision.

Based on the analysis of the game relationship between the construction enterprise and the supervision department, this paper structures the evolutionary game model of green construction 
supervision by using replicated dynamic equation. By means of Jacobin matrix and other nonlinear system analysis methods, this paper studies the stability of the system under static and dynamic supervision strategy, and the impact of changes in regulatory conditions on green construction. This paper looks forward to offering countermeasures and suggestions for green construction supervision in China.

\section{Evolutionary Game Model}

Model Description and Hypothesis. Assuming that the construction enterprises adopt green construction measures and through the inspection of the regulatory authorities, the reward $R_{1}$. The construction enterprises do not take green construction measures and found by the regulatory authorities, subject to punishment $P_{1}$. Construction enterprises adopt green construction measures, the effectiveness $G_{1}, G_{1}>0$ or $G_{1}<0$.

The cost of green construction supervision for the regulatory authorities is $C_{2}$, including labor costs, travel expenses and monitoring fees. Construction enterprises adopt green construction measures, the total social welfare $G_{2}$. If construction enterprises do not carry out green construction, and the regulatory authorities have not taken regulatory measures, it will be punished $P_{2}$, including the punishment of the higher authorities and the criticism of public opinion. If construction enterprises do not carry out green construction, regulatory authorities to take regulatory measures will be rewarded $R_{2}$.

According to the above assumptions, Game payment matrix of construction enterprise and supervision department shows in the Table 1.

Table 1 Game payment matrix of construction enterprise and supervision department

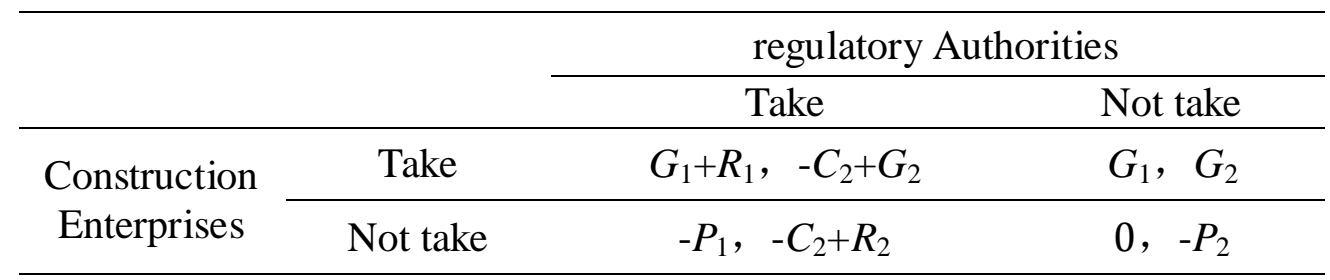

Model Calculation. Suppose that the probability of green construction strategy is $x$, then the probability of adopting non green construction strategy is 1-x. Regulatory authorities to take the probability of regulatory strategy is $y$, then the probability of adopting non regulatory strategy is $1-y$.

The expected return of Construction enterprises to adopt green construction strategy is $E_{1 \mathrm{Y}}$,

$E_{1 Y}=y\left(G_{1}+R_{1}\right)+(1-y) G_{1}$

The expected return of Construction enterprises not to adopt green construction strategy is $E_{1 \mathrm{~N}}$,

$E_{1 N}=y\left(-P_{1}\right)$

Average expected return of construction enterprises is,

$\bar{E}_{1}=x E_{1 Y}+(1-x) E_{1 N}$

According to the Malthusian dynamic equation[11], the replicated dynamic equation of the construction enterprises can be described by this,

$$
F(x)=\frac{d x}{d t}=x\left(E_{1 Y}-\bar{E}_{1}\right)=x(1-x)\left(y R_{1}+G_{1}+y P_{1}\right)
$$

The expected return of Regulatory Authorities to adopt regulatory strategy is $E_{2 \mathrm{Y}}$,

$$
E_{2 Y}=x\left(-C_{2}+G_{2}\right)+(1-x)\left(-C_{2}+R_{2}\right)
$$

The expected return of Regulatory Authorities not to adopt regulatory strategy is $E_{2 \mathrm{~N}}$, 


$$
E_{2 N}=x G_{2}+(1-x)\left(-P_{2}\right)
$$

Average expected return of Regulatory Authorities is,

$$
\bar{E}_{2}=y E_{2 Y}+(1-y) E_{2 N}
$$

According to the Malthusian dynamic equation, the replicated dynamic equation of the Regulatory Authorities can be described by this,

$$
F(y)=\frac{d y}{d t}=y\left(E_{2 Y}-\bar{E}_{2}\right)=y(1-y)\left(R_{2}-C_{2}-x R_{2}+P_{2}-x P_{2}\right)
$$

The replicator dynamic equation of the system (Eq.9) is obtained by formula Eq.4, Eq.8.

$$
\left\{\begin{array}{l}
F(x)=\frac{d x}{d t}=x\left(E_{1 Y}-\bar{E}_{1}\right)=x(1-x)\left(y R_{1}+G_{1}+y P_{1}\right) \\
F(y)=\frac{d y}{d t}=y\left(E_{2 Y}-\bar{E}_{2}\right)=y(1-y)\left(R_{2}-C_{2}-x R_{2}+P_{2}-x P_{2}\right)
\end{array}\right.
$$

When $(F(x), F(y))=(0,0)$, we get 5 equilibrium points of the system $E_{1}(0,0), E_{2}(0,1), E_{3}(1,0)$, $E_{4}(1,1), \quad E_{5}=\left(\frac{R_{2}+P_{2}-C_{2}}{R_{2}+P_{2}},-\frac{G_{1}}{R_{1}+P_{1}}\right)$

Stability Analysis of Evolutionary Game. Friedman proposed that, by analyzing local stability of the system Jacobian matrix, we can analyze the stability of equilibrium points in evolutionary systems[12]. The Jacobian matrix of the system can be described by this,

$$
J=\left[\begin{array}{ll}
\partial F(x) / \partial x & \partial F(x) / \partial y \\
\partial F(y) / \partial x & \partial F(y) / \partial y
\end{array}\right]=\left[\begin{array}{cc}
(1-2 x)\left(y R_{1}+G_{1}+y P_{1}\right) & x(1-x)\left(R_{1}+P_{1}\right) \\
y(1-y)\left(-R_{2}-P_{2}\right) & (1-2 y)\left(-C_{2}+R_{2}-x R_{2}+P_{2}-x P_{2}\right)
\end{array}\right]
$$

According to the stability analysis method of ordinary differential equation, if all the characteristic value of Jacobian matrix of the system have negative real part, then the zero solution of the system is asymptotically stable. Therefore, if an equilibrium point corresponding to the Jacobian matrix determinant value $\operatorname{det}(J)>0, \operatorname{tr}(J)<0$, then the point is the local asymptotic stability point of the system in the evolution process.

Table 2 Stability Analysis

\begin{tabular}{ccc}
\hline Equilibrium Point & $\operatorname{det}(\boldsymbol{J})$ & $\boldsymbol{t r}(\boldsymbol{J})$ \\
\hline$(0,0)$ & $G_{1}\left(R_{2}+P_{2}-C_{2}\right)$ & $G_{1}+R_{2}+P_{2}-C_{2}$ \\
$(0,1)$ & $\left(R_{1}+G_{1}+P_{1}\right)\left(C_{2}-R_{2}-P_{2}\right)$ & $R_{1}+G_{1}+P_{1}+C_{2}-R_{2}-P_{2}$ \\
$(1,0)$ & $G_{1} C_{2}$ & $-G_{1}-C_{2}$ \\
$(1,1)$ & $\left(-R_{1}-G_{1}-P_{1}\right) C_{2}$ & $C_{2}-R_{1}-G_{1}-P_{1}$ \\
$\left(X^{*}, Y^{*}\right)$ & + & 0 \\
\hline
\end{tabular}

The stability of equilibrium points under different conditions is discussed:

(1) If and only if $G_{1}<0, R_{2}+P_{2}-C_{2}<0,(0,0)$ is a stable equilibrium point of system evolution. At this time, the benefits of green construction of construction enterprises are negative. The cost of supervision is too large, which is larger than the sum of the total welfare of green construction and the punishment of the supervision department. So as to form the situation of construction enterprise non green construction, supervision department non regulatory.

(2) If and only if $R_{1}+G_{1}+P_{1}<0, C_{2}-R_{2}-P_{2}<0,(0,1)$ is a stable equilibrium point of system evolution. At this time, the benefits of green construction of construction enterprises is negative, and the absolute value is larger than the sum of the green construction award and the non-green construction punishment. Therefore, even if the regulatory authorities to take the probability of $100 \%$ regulatory strategy, construction enterprises still take the probability of green construction by $0 \%$.

(3) If and only if $G_{1}>0,(1,0)$ is a stable equilibrium point of system evolution. At this time, the 
effectiveness of the green construction of construction enterprises is positive, so in the case of regulatory authorities do not take regulatory measures, the construction enterprises to take the probability of $100 \%$ green construction.

(4) Since the supervision cost $\mathrm{C}_{2}>0$ is constant, so that $\left(-R_{1}-G_{1}-P_{1}\right) C_{2}>0$ and $C_{2}-R_{1}-G_{1}-P_{1}<0$ cannot be established at the same time. $(1,1)$ is not a stable equilibrium of system evolution.

(5) Since $\operatorname{det}(J)>0, \operatorname{tr}(J)=0,\left(X^{*}, Y^{*}\right)$ is a pair of pure imaginary numbers, we can determine that $\left(X^{*}, Y^{*}\right)$ is the non-asymptotic stability center point of the system.

In the current level of technology, green construction generally produce negative benefits, that is $G_{1}<0<0$. For regulators, social pressure of public opinion and superior departments of punishment caused by poor regulatory effect must be larger than the cost of supervision, that is $R_{2}+P_{2}-C_{2}>0$. When construction enterprises are not green construction, the supervision departments will take the "The loss outweighs the gain " punishment policy, in order to achieve the purpose of punishment, that is $R_{1}+P_{1}>-G_{1}$, or $R_{1}+G_{1}+P_{1}>0$.

Based on the above analysis, the following research and discussion will be under the premise of $G_{1}<0, R_{2}+P_{2}-C_{2}>0, R_{1}+G_{1}+P_{1}>0$. So the boundary conditions of situation (1)-(3) can not be achieved, so there is no stable equilibrium point.

\section{Dynamic Incentive and Punishment Strategy}

Dynamic Incentive Strategy Analysis. The higher the probability $x$ of green construction of construction enterprises, the smaller the negative impact on the environment, the regulatory authorities will also be given a higher reward. $x$ and $R_{1}$ can be idealized as a positive relation, then there: $R_{1}(x)=x R$, which $R$ is the highest reward.

Under dynamic penalty mechanism, the replicator dynamic equation of the system is shown in Eq.10.

$$
\left\{\begin{array}{l}
F(x)=\frac{d x}{d t}=x(1-x)\left[y R_{1}(x)+G_{1}+y P_{1}\right] \\
F(y)=\frac{d y}{d t}=y(1-y)\left(-C_{2}+R_{2}-x R_{2}+P_{2}-x P_{2}\right)
\end{array}\right.
$$

5 equilibrium points of the system are obtained:

$$
E_{1}^{\prime}(0,0), \quad E_{2}^{\prime}(0,1), \quad E_{3}^{\prime}(1,0), \quad E_{4}^{\prime}(1,1), \quad E_{5}^{\prime}\left(\frac{R_{2}+P_{2}-C_{2}}{R_{2}+P_{2}}, \frac{-G_{1}\left(R_{2}+P_{2}\right)}{R\left(R_{2}+P_{2}-C_{2}\right)+P_{1}\left(R_{2}+P_{2}\right)}\right)
$$

At this point, the Jacobian matrix of the system is:

$$
J=\left[\begin{array}{cc}
(1-2 x)\left[y R_{1}(\mathrm{x})+G_{1}+y P_{1}\right]+x y(1-x) R_{1}^{\prime}(x) & x(1-x)\left[R_{1}(x)+P_{1}\right] \\
y(1-y)\left(-R_{2}-P_{2}\right) & (1-2 y)\left(-C_{2}+R_{2}-x R_{2}+P_{2}-x P_{2}\right)
\end{array}\right]
$$

Similar to the analysis of article $2.3, E_{1}^{\prime} 、 E_{2}^{\prime} 、 E_{3}^{\prime} 、 E_{4}^{\prime} 、 E_{5}^{\prime}$ are not stable equilibrium points of the system.

\section{Dynamic Penalty Strategy Analysis.}

(1)Stability analysis of equilibrium point under dynamic penalty strategy

The probability $(1-x)$ of non-green construction of construction enterprises is higher, the greater the negative impact on the environment, the regulatory authorities will also give higher punishment. (1-x) and $P_{1}$ can be idealized as a positive relation, then there: $P_{1}(x)=(1-x) P$, which $P$ is the highest punishment.

Under dynamic penalty mechanism, the replicator dynamic equation of the system is shown in Eq.11. 


$$
\left\{\begin{array}{l}
F(x)=\frac{d x}{d t}=x(1-x)\left[y R_{1}+G_{1}+y P_{1}(x)\right] \\
F(y)=\frac{d y}{d t}=y(1-y)\left(-C_{2}+R_{2}-x R_{2}+P_{2}-x P_{2}\right)
\end{array}\right.
$$

5 equilibrium points of the system are obtained:

$$
E_{1}^{\prime \prime}(0,0), \quad E_{2}^{\prime \prime}(0,1), \quad E_{3}^{\prime \prime}(1,0), \quad E_{4}^{\prime \prime}(1,1), \quad E_{5}^{\prime \prime}\left(\frac{R_{2}+P_{2}-C_{2}}{R_{2}+P_{2}}, \frac{-G_{1}\left(R_{2}+P_{2}\right)}{R_{1}\left(R_{2}+P_{2}\right)+C_{2} P}\right)
$$

At this point, the Jacobian matrix of the system is:

$$
J=\left[\begin{array}{cc}
(1-2 x)\left[y R_{1}+G_{1}+y P_{1}(x)\right]+x y(1-x) P_{1}^{\prime}(x) & x(1-x)\left[R_{1}+P_{1}(x)\right] \\
y(1-y)\left(-R_{2}-P_{2}\right) & (1-2 y)\left(-C_{2}+R_{2}-x R_{2}+P_{2}-x P_{2}\right)
\end{array}\right]
$$

Similar to the analysis of article $2.3, E_{1}^{\prime \prime}(0,0), E_{2}^{\prime \prime}(0,1), E_{3}^{\prime \prime}(1,0), E_{4}^{\prime \prime}(1,1)$ are not stable equilibrium points of the system. Take $E_{5}^{\prime \prime}$ into the Jacobian matrix and compute $\operatorname{det}\left[J\left(E_{5}^{\prime \prime}\right)\right]$ and $\operatorname{tr}\left[J\left(E_{5}^{\prime \prime}\right)\right]$ as shown in Eq.12, Eq.13.

$$
\begin{aligned}
& \operatorname{det}\left[J\left(E_{5}^{\prime \prime}\right)\right]=-\frac{G_{1} C_{2}\left(R_{1}+\frac{C_{2} P}{R_{2}+P_{2}}+G_{1}\right)\left(R_{2}+P_{2}-C_{2}\right)}{R\left(R_{2}+P_{2}\right)+C_{2} P} \\
& \operatorname{tr}\left[J\left(E_{5}^{\prime \prime}\right)\right]=\frac{G_{1} C_{2} P\left(R_{2}+P_{2}-C_{2}\right)}{\left(R_{2}+P_{2}\right)\left[R_{1}\left(R_{2}+P_{2}\right)+C_{2} P\right]}
\end{aligned}
$$

Known that $G_{1}<0, R_{2}+P_{2}-C_{2}>0$, It is easy to prove that $\operatorname{det}\left[J\left(E_{5}^{\prime \prime}\right)\right]>0, \operatorname{tr}\left[J\left(E_{5}^{\prime \prime}\right)\right]<0$, so $E_{5}^{\prime \prime}$ is the stable equilibrium point.

(2) Analysis of Factors Influencing Stable Equilibrium

The stable equilibrium point of system evolution $E_{5}^{\prime \prime}$ under dynamic penalty strategy can be expressed as Eq.14.

$$
\left\{\begin{array}{l}
x^{* *}=\frac{R_{2}+P_{2}-C_{2}}{R_{2}+P_{2}} \\
y^{* * *}=\frac{-G_{1}\left(R_{2}+P_{2}\right)}{R_{1}\left(R_{2}+P_{2}\right)+C_{2} P}
\end{array}\right.
$$

After taking the derivative of $x^{* *}$ and $y^{* *}$ with respect to $R_{2}+P_{2}$ and $C_{2}$ respectively, we can get the equation Eq.15, Eq.16.

$$
\begin{aligned}
& \left\{\begin{array}{l}
x^{* * \prime}\left(R_{2}+P_{2}\right)>0 \\
y^{* * \prime \prime}\left(R_{2}+P_{2}\right)>0
\end{array}\right. \\
& \left\{\begin{array}{l}
x^{* * \prime \prime}\left(\mathrm{C}_{2}\right)<0 \\
y^{* * \prime \prime}\left(C_{2}\right)<0
\end{array}\right.
\end{aligned}
$$

By Eq. 15 can be obtained that, to improve the reward $\left(R_{2}\right)$ for regulatory authorities when investigating the non green construction and penalty $\left(P_{2}\right)$ for regulatory authorities when not investigating the non green construction, can improve the construction enterprise green construction probability (x) and regulatory regulatory probability $(y)$.

By Eq.16 can be obtained that, to reduce the regulatory cost $\left(C_{2}\right)$ can increase the probability of green construction $(x)$ and the regulatory probability $(y)$.

After taking the derivative of $y^{* *}$ with respect to $G_{1} 、 R_{1}$ and $P$ respectively, we can get the equation Eq.17, Eq.18, Eq.19. 


$$
\begin{aligned}
& y^{* * 1}\left(G_{1}\right)<0 \\
& y^{* * \prime \prime}\left(R_{1}\right)<0 \\
& y^{* * \prime}(P)<0
\end{aligned}
$$

By Eq.17, Eq.18, Eq.19 can be obtained that, to improve the effectiveness of green construction enterprises $\left(G_{1}, G_{1}<0\right)$, the construction enterprise green construction incentives $\left(R_{1}\right)$ and the highest punishment $(P)$ of non green construction can reduce the regulatory supervision probability $(y)$.

\section{Conclusion}

In this paper, the evolutionary game theory is applied to the study of green construction supervision, from the micro and quantitative point of view, the paper analyzes the game between the construction enterprise and the supervision department. This paper draws the following conclusions.

(1) In the current level of green construction and supervision of the status quo, if the regulatory authorities to take a static reward and punishment strategy, then there is no stable equilibrium point in the game process. If the dynamic penalty strategy is adopted, there is an evolutionary stable equilibrium point in the system. If the dynamic reward strategy is adopted, there will be no stable equilibrium point.

(2) Under the dynamic penalty strategy, it can improve the level of stable equilibrium point by changing some boundary conditions: First, strengthen publicity and increase the importance of green construction, so as to improve the effectiveness of the regulatory authorities to investigate the non green construction awards $\left(R_{2}\right)$ and as a result of the penalty $\left(P_{2}\right)$. Second, to co-ordinate arrangements for the regulatory authorities, the scientific implementation of multi-channel to reduce regulatory costs $\left(C_{2}\right)$.

\section{References}

[1] Y.Q. Huang: Supervision Test and Cost of Construction, Vol. 20 (2001) No.3, p.100. (In Chinese)

[2] L. XU, L.N. Dong and J.J. Yin: Construction Economics, Vol. 37 (2016) No.3, p.106. (In Chinese)

[3] X.W. Xiao, D.K. Feng: Construction Technology, Vol. 42 (2013) No.1, p.12. (In Chinese)

[4] X. Wang: Study of Promoting the Application of Green Construction in Engineering Construction Enterprises (MS., Chang'an University, China 2015), p.82. (In Chinese)

[5] Y. Lin: Research on Driving Forces for Construction Enterprises to Implement Green Construction (MS., Chongqing University, China 2012), p.36. (In Chinese)

[6] J.M. Smith and G.R. Price: Resonance, Vol. 10 (1973) No.11, p.5.

[7] L.Q. Zhang: Economic Science, Vol. 15 (2001) No.3, p.103. (In Chinese)

[8] B.H. Guo, Z.G. Fang and Q. Liu: Chinese Journal of Management Science, Vol. 20 (2012) No.4, p.79. (In Chinese)

[9] J. Chen, H. Yin and F. Xie: Science \& Technology Progress and Policy, Vol. 31 (2014) No.5, p. 1

[10] W. Zhang, G.G. Zhou, and J.Cao: China Population Resources and Environment, Vol. 171 (2014) No.S3, p.108. (In Chinese) 
[11] J W Weibull: Southern Economic Journal, Vol. 22 (1995) No.88, p.43.

[12]D Friedman. : Econometrica, Vol. 59 (1991) No.3, p.637. 